\title{
Advanced Micro-Actuator/Robot Fabrication Using Ultrafast Laser Direct Writing and Its Remote Control
}

\section{Sangmo Koo}

Department of Mechanical Engineering, Incheon National University, Incheon 22012, Korea; skoo@inu.ac.kr; Tel.: +82-32-835-8036

Received: 8 November 2020; Accepted: 26 November 2020; Published: 30 November 2020

\begin{abstract}
Two-photon polymerization (TPP) based on the femtosecond laser (fs laser) direct writing technique in the realization of high-resolution three-dimensional (3D) shapes is spotlighted as a unique and promising processing technique. It is also interesting that TPP can be applied to various applications in not only optics, chemistry, physics, biomedical engineering, and microfluidics but also micro-robotics systems. Effort has been made to design innovative microscale actuators, and research on how to remotely manipulate actuators is also constantly being conducted. Various manipulation methods have been devised including the magnetic, optical, and acoustic control of microscale actuators, demonstrating the great potential for non-contact and non-invasive control. However, research related to the precise control of microscale actuators is still in the early stages, and in-depth research is needed for the efficient control and diversification of a range of applications. In the future, the combination of the fs laser-based fabrication technique for the precise fabrication of microscale actuators/robots and their manipulation can be established as a next-generation processing method by presenting the possibility of applications to various areas.
\end{abstract}

Keywords: two-photon polymerization; micro-actuator; femtosecond laser; remote control

\section{Introduction}

Motion is an essential element in maintaining the life of living organisms, and life has evolved to induce efficient movement for a long time. Scientists have been steadily making efforts to develop microscale actuators inspired by the mechanisms of the movement organs of life forms. Micro-actuators are small in size and capable of non-contact/non-invasive manipulation, and they can be used in various applications such as targeted drug delivery [1,2], non-invasive surgery, and cell manipulation [3] with additional functionalization. Moreover, unlike conventional macroscale actuators, interest is increasing in micro-actuators that can precisely operate in harsh conditions such as narrow passages, enclosed conditions, and high viscosity environments. In particular, research into bio/medical technology advancement has been accelerated due to the promise of control under in vivo-like conditions.

Conventional microscale actuators have been fabricated using various techniques such as photolithography [4], 3D printing [5], shape memory [6], and soft lithography [7]. A fabricated micro-actuator can be manipulated by various energy sources. A commonly used propulsion mechanism is a chemical-based actuation mechanism that is based on the conversion of chemical energy into propulsion $[8,9]$. In this process, the actuator's driving force can be obtained from the concentration gradient of molecules or the microbubble generation during chemical decomposition. Actuation through direct chemical decomposition is easy to fabricate and induce, but biocompatibility issues can arise when chemical substances remain due to incomplete chemical degradation [10]. To overcome these limitations, actuation can be induced using biocompatible chemicals such as enzymes [11] and urea [12]. Moreover, several types of methods such as magnetic [13,14], optical [15], and acoustic [16] can be used 
to create a microscale actuator's remote control. The advantages of a long lifespan, on-demand motion control, and excellent biocompatibility have shown great potential for in vivo research. Nonetheless, most work remains in the early stages, and related technologies are being developed through the efforts of many researchers. As the demand for three-dimensional (3D) complexes with high-precision micro-actuators increases, new fabrication methods are being required. As a solution to this, two-photon polymerization (TPP) based on the two-photon absorption (TPA) principle was devised to fabricate precise 3D micro-structures without the use of photomasks or iterative processes [17-20]. However, due to the lack of mechanical strength, electrical conductivity, and magnetic and optical properties of structures fabricated by TPP [21], additional processes are required for the remote manipulation or driving of actuators by magnetic, optical, and acoustic control.

In this review, we explore the driving/control methods of micro-actuators fabricated based on the TPP technique. We summarize the progress of the remote control of 3D micro-actuators/robots concerning the fabrication processes, actuation mechanisms, limitations, and reviews of the potential applications and challenges to be solved.

\section{Micro-Actuator Fabrication}

\section{Principle of Two-Photon Polymerization}

TPP can be explained by the non-linear optical property of TPA described by Maria Goeppert-Mayer in 1931 [22]. TPA is the interaction between a single atom/molecule and multiple photons during a single quantum event, which occurs in the photo-excitation process from a lower quantum state to an excited quantum state of an atom (or molecule). When a single photon has energy above the bandgap of the material, photon energy is absorbed by the excitation of electrons from the valence band (VB) to the conduction band (CB) by single-photon absorption. However, even if the photon energy is less than the bandgap, electrons can be excited by multiple photons through a virtual state when a very high photon density is provided to a material. Therefore, the simultaneous/sequential action of two photons provides enough energy to induce this transition during the TPA process [23]. Since TPA requires very high energy, it can be induced by using femtosecond (fs) laser with a short pulse duration, which makes it possible to obtain a sufficient optical electric field for TPA to be feasible. TPA can be explained by two mechanisms: sequential TPA and simultaneous TPA (Figure 1a). Sequential excitation is an electronic transition to an excited energy state via an intermediate state. The absorbed species are transferred to the actual intermediate state by first photon absorption, and this species is transformed into an excited state by the subsequent absorption of the second photon [23]. The excited electrons in the intermediate state are excited to a higher quantum state by absorbing a second photon with the same energy. In contrast, electrons are excited to a higher state by simultaneously absorbing two photons in one quantum state without the excited intermediate state in simultaneous TPA. The absorption process is considered the initial interaction of atoms/molecules and photons, and it form a temporary virtual energy state above the ground state. When the second photon arrives before the decay of the photon in the virtual state within a short time period, the two photons can be absorbed at the same time, thereby becoming exited to the higher state and transcending the energy bandgap. 
a

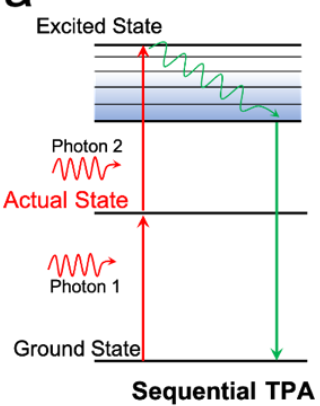

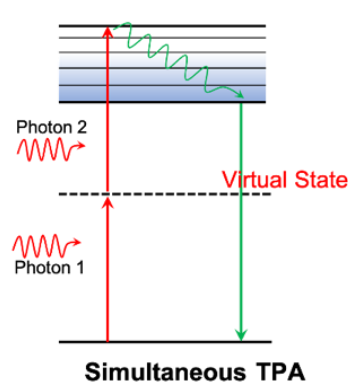

Simultaneous TPA b

Excited State

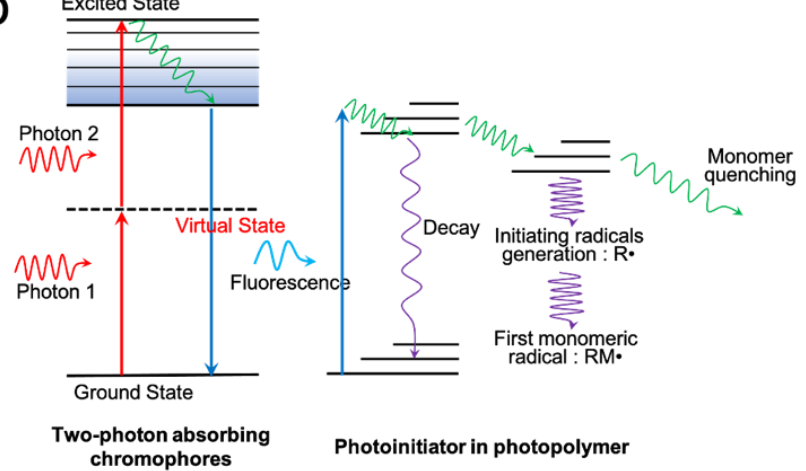

C $\begin{aligned} \text { Initiation } \quad: & I \stackrel{h v}{\longrightarrow} I^{*} \rightarrow R \bullet \\ & S \stackrel{2 h v}{\longrightarrow} S^{*} \cdots \stackrel{I}{\rightarrow} I^{*} \rightarrow R \bullet \\ & R \bullet+M \rightarrow R-M \bullet\end{aligned}$

Propagation : $\quad R-M \bullet \stackrel{M}{\longrightarrow} R-M-M \bullet \rightarrow \cdots \stackrel{M}{\longrightarrow} R(M)_{n} \bullet$

Termination : $R(M)_{n} \bullet+R(M)_{m} \bullet \rightarrow R(M)_{m+n} R$

$$
\text { or } \quad \rightarrow R(M)_{n}+R(M)_{m}
$$

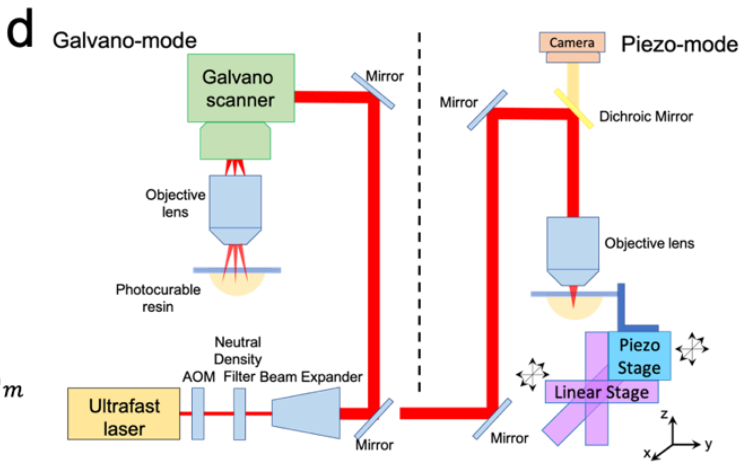

Figure 1. The principle of the two-photon polymerization (TPP) and experimental setup. (a) Schematic diagram of two-photon absorption (TPA) — sequential and simultaneous TPA; (b) schematic diagram of photopolymerization by the transformation process of photon energy; (c) schematic of the two-photon polymerization process (S: photosensitizer; $S^{*}$ : excited states of the photosensitizer; hv: Planck's equation energy for each adsorbed photon; I: photoinitiator (PI); I*: excited states of the PI; R: radical; and M: monomer); and (d) schematic illustration of a typical TPP experimental configuration: galvano mode (left) and piezo mode (right).

When the TPA process takes place on photocurable resin materials, photo-induced polymerization reactions occur, which allow for 3D micro/nanoscale structure fabrication. For TPA polymerization, two photons are simultaneously absorbed within a tightly focused small focal volume using a high numerical aperture (N.A.) objective lens in a photocurable resin, which causes a chemical reaction between the photo-initiator molecule and the monomers by femtosecond pulses with an ultrahigh-peak intensity and a very short pulse duration [24,25].

A general photocurable resin is composed of a photoinitiator (PI) for radical generation, a monomer or oligomer to form the bonding between molecules, crosslinkers, photosensitizers, quenchers, and solvents for dilution [26]. Looking at the properties of the photocurable resin's components in detail, the PI can be classified into two types-radical and cationic, depending on what material needs to be generated. The monomers or oligomers, constituent units of the polymer network, determine the physical/chemical and mechanical properties of the photo-polymerized structure. The solvent can control the viscosity of the photocurable resin, which is an important component for the stability of a photo-polymerized structure. By using photocurable resin with a high viscosity, the photo-polymerized structure can be stably maintained, but it takes a long time in the development process. In contrast, the mechanical stability of a photo-polymerized structure is not guaranteed, but the development process can be completed in a short time with a low-viscosity photocurable resin. To achieve an efficient fabrication process, it is necessary to consider the factors required for each component. The PI and monomer or oligomer should not be thermally damaged or ablated during the TPP process, and photocurable resin should be transparent at the TPA wavelength. At the same time, the PI must not only absorb the two-photon wavelength but must also satisfy high active moieties and radical 
generation. In Malinauskas's research, a photo-polymerization process using material without a PI was reported, and the highest resolution of the 3D structure with the sub-100 nm resolution was experimentally achieved in a non-photosensitive resist [27]. However, the widest processing window was observed for photo-sensitized resists, not non-photosensitive resists.

During the irradiation of the tightly focused femtosecond laser beam into the photocurable resin, avalanche ionization plays an important role in chemical bond breaking and polymerization [28]. Valence electrons in a PI are excited via the fluorescence induced by a photosensitizer. These excited PIs are partitioned into three types of transformations such as the decay back to an initial state of a PI with light or heat emissions, quenching with oxygen or quenching agents, and a chemical reaction yielding an initiator species (e.g., radical) for polymerization (Figure 1b). In the initiation step, the reactive initiating species such as radicals are generated by absorbing the excitation energy. These reactive free radicals attack the $\mathrm{C}=\mathrm{C}$ bonds of monomers and form monomers containing free electrons. Additionally, the generated radicals react with monomers or oligomers to generate monomer radicals, and the resulting monomer radicals are polymerized into high-molecular-weight materials by continuing the propagation process until they are terminated with other types of radicals. This process refers to the propagation step. In the termination step, two radicals meet and the reaction stops [29] (Figure 1c).

Generally, a TPP fabrication system consists of an ultrafast (femtosecond) laser source and a moving part (piezo mode [30] or galvano mode [31]) that controls the scanning of the focused laser beam within a photocurable resin (Figure 1d). The photopolymerization process is also possible even with low-cost lasers that emit picosecond [32,33] or nanosecond [34] pulses and continuous waves (CWs) [35] if appropriate exposure energy is delivered to the photopolymerization material. Considering its short pulse duration and high peak power, however, a Ti:sapphire near-infrared fs-laser [36-38] or Er-doped femtosecond fiber laser [39,40] system is used as a light source for an efficient TPA process. The beam expander reduces the divergence angle of the laser beam, and this expanded beam can be tightly focused into the photocurable resin using a high N.A. objective lens. The exposure time is controlled by a mechanical shutter, and the processes are real-time monitored by a CMOS (complementary metal-oxide semiconductor)/CCD (charge-coupled device) camera.

For the moving part, polymerization through the movement of a laser beam inside a photocurable resin can be realized in two ways. In the piezo mode, the sample is placed on a 3D piezoelectric stage and moves along the $\mathrm{x}-\mathrm{y}-\mathrm{z}$-axis according to the machining geometry, so the structure is fabricated according to the laser trajectory. It is possible to further reduce the focal volume using a high N.A. oil immersion objective lens, resulting in a precise structure with a high resolution. However, the maximum height of a fabricated feature is limited by the working distance of an objective lens. To overcome this limitation, dip-in direct laser writing (dip-in DLW) has been developed [41]. In the galvano mode, scanning is performed in the $\mathrm{x}$ and $\mathrm{y}$ directions using a focused 2D galvanometer scanner, and the focus position is changed in the z-direction using a 1D piezoelectric stage. This method is superior to other methods in that it is capable of high-throughput processing and it is possible to fabricate a 3D structure with a high height by moving the piezoelectric stage in the z-direction.

3D models can be generated using computer-aided design (CAD) programs such as SolidWorks, AutoCAD, 3DS Max, and Fusion360, which can be converted into the Standard Tessellation Language (STL) file format which stores information about the surface of the 3D model in the form of triangulated sections [20]. To fabricate a structure with nanoscale features, more precise position information defining a surface is required, and this can be obtained by increasing the number of triangulated sections. After a 3D structure is divided into a sequence of 2D horizontal cross-sections in the depth direction and continuous processing is performed for each divided layer, a nanoscale 3D structure with a high resolution can be fabricated.

Photocurable resins have been developed with a wide variety of materials including popular UV lithographic photoresists (e.g., SU-8), various hybrid sol-gel materials (e.g., ORMOCER ${ }^{\circledR}[40]$, ORMOCOMP ${ }^{\circledR}[42]$, and SZ2080 [43,44]), and biomaterials [45]. A commercial material such as SU-8 
is inferior in that it is difficult to modify the material's properties as desired. Therefore, to use a commercial material for specific purposes requires additional functionalization. Research has been conducted to develop new candidate materials for an effective TPP process. For example, components such as nanomaterials (e.g., nanoparticles and nanowires) have been applied as active components to induce customized additional functions in recent years [46-49]. For the efficient fabrication and motion control of an actuator, the appropriate modification and synthesis of photocurable resin is an important issue.

\section{Manipulation of Micro Actuator}

The fabrication of micro-actuators/robots by TPP has attracted attention due to its specific strength in that a variety of materials can be printed and integrated within a 3D micro actuator/robot for the functionalization of the remote control of the actuator. Though high-resolution, complex 3D structure fabrication is possible, a polymeric structure that is fabricated using only photocurable resins intrinsically lacks mechanical strength, electrical conductivity, and magnetic and optical properties. Hence, new approaches are needed to achieve efficient actuation and remote manipulation. Various methods have been developed for efficient actuation and control, and they can be classified into two categories: material-based and structural-based treatments. A material-based treatment is a modification of the photocurable resin itself; on the contrary, a structural-based treatment is a method of imparting function to a fabricated structure. For example, mixing nanomaterials into a photocurable resin for functionalization is a material-based treatment [46], and surface coatings on the outer surface of a fabricated structure via diverse deposition methods such as chemical vapor deposition (CVD), electron beam (e-beam) deposition, physical vapor deposition (PVD), and sputtering are structural-based treatments [50].

For reciprocal motions, it is difficult to avoid zero net movements. This could be solved by non-reciprocal movements such as bionic scallop and corkscrew motions [51]. Moreover, rotational motion could be converted into a translational motion using a helical structure that mimics the swimming of bacterium by rotating the bacterial flagella [52]. Considering the environment in which a micro-actuator/robot operates where viscosity is dominant, it is more efficient to move an actuator using different and diverse methods such as chemical, magnetic, optical, and acoustic force rather than a load for efficient non-contact/non-invasive movement and manipulation to a targeted location [53].

\subsection{Catalytically Manipulated Micro-Actuator/Robot}

Many studies on the actuation of tubular structures fabricated by photolithography techniques have been performed. A catalytic micro-tubular actuator was fabricated using a rolled-up method and template-assisted electrochemical deposition [8,9,54-57]. A catalytic micro-tubular actuator converts chemical energy into mechanical energy. It generates and emits oxygen bubbles from catalytic microtubular cavities through the decomposition of hydrogen peroxide $\left(\mathrm{H}_{2} \mathrm{O}_{2}\right)$, and this propels the micro-tubular actuator. However, it is difficult to use the rolled-up method to fabricate an asymmetric micro-tubular structure, and TPP is considered an appropriate technique for performing this.

Chen et al. fabricated highly efficient catalytic microtubular motors using TPP and investigated motion behavior under different conditions [58]. Their micro-tubular structure was coated with a metallic layer as a catalyst by evaporation and was able to induce actuation in an $\mathrm{H}_{2} \mathrm{O}_{2}$ solution. The oxygen bubble ejection frequency, which depended on the geometry of the microtubular motors and the concentration of aqueous $\mathrm{H}_{2} \mathrm{O}_{2}$, was investigated using a fixed micro-tubular cavity on a substrate. The high-efficiency propulsion through the catalytic decomposition of $\mathrm{H}_{2} \mathrm{O}_{2}$ improved the speed of the microtubular motor, and the speed of the microtubular motor was enhanced as the $\mathrm{H}_{2} \mathrm{O}_{2}$ solution concentration and cavity length increased. The authors also fabricated a rocket-shaped microtubular motor by taking advantage of TPP, which allowed for the precise machining of 3D arbitrary shapes. A rocket-shape microtubular motor booster showed a much higher average moving speed compared to the single microtubular motors. However, there is a limitation to this method in that an actuator 
using a high concentration of $\mathrm{H}_{2} \mathrm{O}_{2}$ is not suitable for use in an in vivo environment due to biological instability. Therefore, the TPP technique is expected to contribute to the processing of the microtubular actuators of complex 3D shapes with high-speed motion even at low concentrations of $\mathrm{H}_{2} \mathrm{O}_{2}$ for diverse in vivo applications. Li et al. fabricated a pH-responsive micro-actuator consisting of a bendable hydrogel microtube using a density-distribution-controllable, femtosecond Bessel beam. This beam was generated by locally compressing the phase modulation depth of the hologram. This method has the advantage of being a facile, one-step, and single material technique. Diverse shapes (e.g., S-shaped, C-shaped, multi-segment microtubes, and multivalve torsional chiral structures) with tremendous deformation capacities were fabricated using dynamic holographic fabrication and splicing processes. A multi-finger responsive microgripper was fabricated and operated to capture small-sized features (e.g., polystyrene microparticles and neural stem cells) under $\mathrm{pH}$ changes [59].

\subsection{Magnetically Manipulated Micro-Actuator/Robot}

The fabrication of various magnetic-responsive micromachines (e.g., actuators, rotors, and turbines) has been achieved by TPP, and diverse remote/precise manipulation methods have been devised. Since photocurable resin itself does not have ferromagnetic properties, additional modification is required to impart ferromagnetic properties to micro-actuators/robots. In order to introduce magnetism to a structure, $\mathrm{Fe}_{3} \mathrm{O}_{4}$ ferromagnetic nanoparticles can be mixed with the photocurable resin [60-62], or magnetic materials can be coated onto the surface of a pre-fabricated structure [63-65].

For example, for the magnetic manipulation of micro-actuator/robot fabricated using ferromagnetic photocurable resin, an artificial bacterial flagella (ABF) micro-swimmer with a magnetically self-driven helical structure was fabricated [66]. In a different form, a micro-swimmer based on the corkscrew motion was fabricated using magnetic hydrogel [60] (Figure 2a,b). Peter et al. synthesized photopolymerizable ferromagnetic polyethylene glycol-diacrylate (PEG-DA) and trimethylolpropane ethoxylate triacrylate (TMPE-TA) with an acrylate group at the end by mixing them with superparamagnetic $\mathrm{Fe}_{3} \mathrm{O}_{4}$ nanoparticles [67]. Using this material, a hemocompatible micro-swimmer that could be driven by an external magnetic force and absorb/release drugs was fabricated. Moreover, they developed a new method to align doped magnetic nanoparticles along a magnetic field before TPP processing, and an ABF structure that exhibited a wobble-free motion was fabricated. The preparation of a magnetic photocurable resin by mixing magnetic particles has been extended to commercial materials such as SU-8. Suter et al. prepared this by adding $\mathrm{Fe}_{3} \mathrm{O}_{4}$ nanoparticles to a solvent of SU-8 and then diluting the mixture with $\gamma$-butyrolactone to meet the required viscosity for spin coating and $\mathrm{ABF}$ fabrication [68]. This ABF was not only able to be accurately manipulated by an external magnetic field—it also exhibited biocompatibility with a WST-1 proliferation assay. 

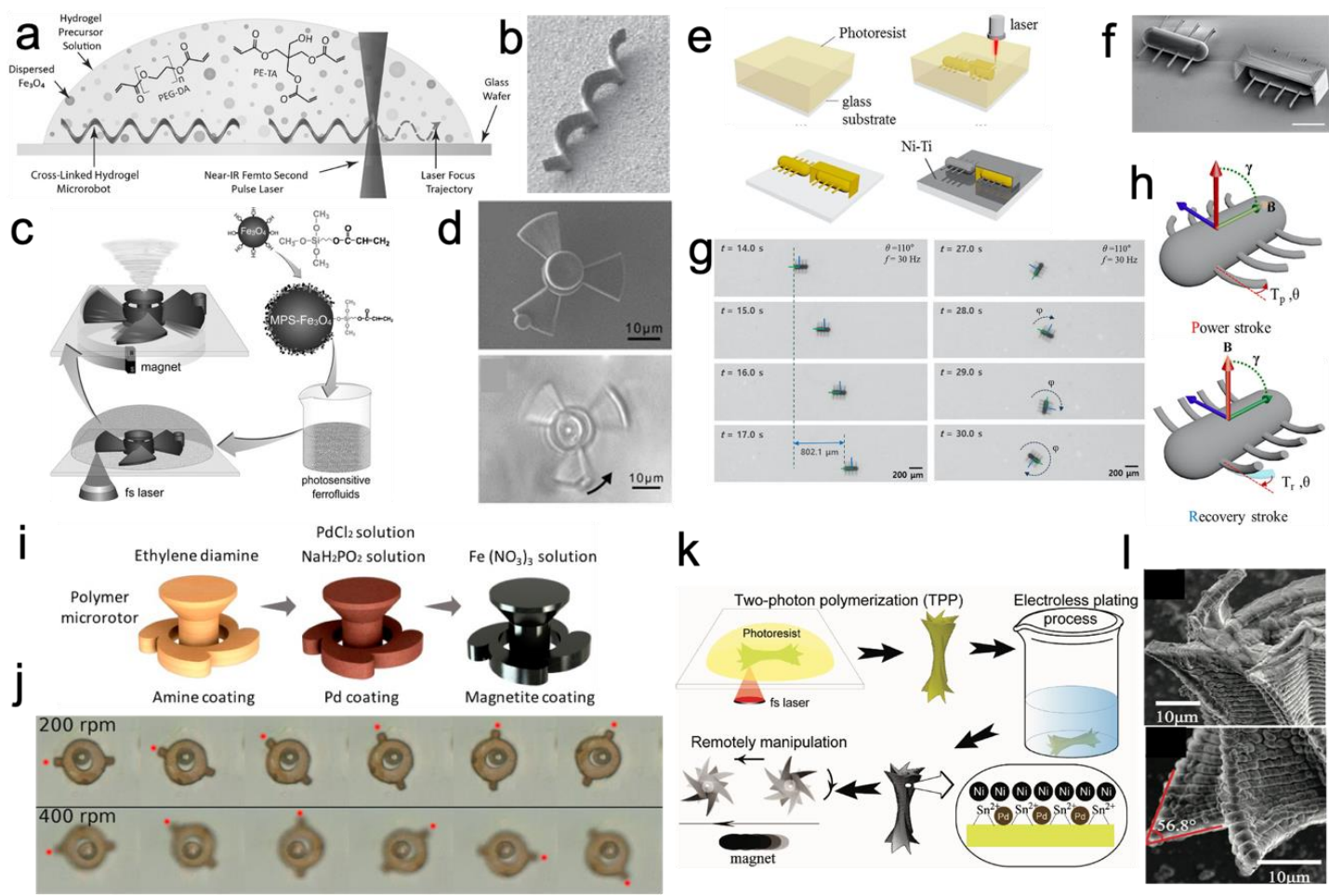

Figure 2. Magnetically manipulated micro-actuators/robots. (a) Fabrication of superparamagnetic hydrogel micro-robots by TPP [60]; (b) SEM image of helical micro-swimmer robot [60] (reproduced from [60] with permission from John Wiley \& Sons, Inc.); (c) procedures of remotely controllable micro-turbine fabrication [61]; (d) optical microscopy images of the micro-turbine in a circumgyration cycle [61] (reproduced from [61] with permission from John Wiley \& Sons, Inc.); (e) ciliary micro-robots fabrication process [63]; (f) SEM images of fabricated ciliary micro-robots with and without a mask structure (scale bar: $100 \mu \mathrm{m}$ ) [63]; (g) time-lapse images of the cilia micro-robot manipulation (translational motion and rotational motion) [63]; (h) schematics of magnetic actuation for the ciliary micro-robot with power stroke (Tp) and recovery stroke (Tr) [63] (reproduced from [63] with permission from Springer Nature); (i) electroless magnetite plating of a polymeric micro-rotor fabricated by TPP [69]; (j) subsequent frames recorded at $50 \mathrm{fps}$ with different rotation speeds (200 and $400 \mathrm{rpm}$ ) [69] (reproduced from [69] with permission from MDPI); (k) fabrication process of 3D magnetically driven micromachine [70]; and (1) SEM image of polymeric micromachine with an electroless magnetic nickel-phosphorus layer [70] (reproduced from [70] with permission from American Chemical Society).

The shape of the fabricated structure was not only helical (e.g., ABF) but also a more complex 3D shape to satisfy various purposes. From Tian's research, it was found that a ferrofluidic photoresist by doping the synthesized $\mathrm{Fe}_{3} \mathrm{O}_{4}$ magnetic nanoparticles into an original photoresist could be, and 6-(methacryloyloxy) hexanoic acid was used for the homogeneous dispersion of magnetic nanoparticles [71]. To examine the effectiveness of a ferrofluidic photoresist, a magnetic micro-spring structure was fabricated, and the performance was confirmed by changing the shape of the spring (e.g., elongation and bending) according to the change of the external magnetic force. Wang et al. also fabricated micro-springs that were connected on one end to a sphere and on the other end to a substrate with an anchor after doping a photoresist with surface-modified $\mathrm{Fe}_{3} \mathrm{O}_{4}$ nanoparticles [62]. Various motions such as bending, swinging, and stretching were achieved by applying magnetic gradients to this structure using an external ferromagnet. A rotor-shaped structure was fabricated using ferrofluidic resin composed of methacrylate and $\mathrm{Fe}_{3} \mathrm{O}_{4}$ nanoparticles [61] (Figure 2c,d). Since the homogeneous dispersion of nanoparticles is a critical factor for successful rotor rotation in a strong magnetic field, 3-(trimethoxysilyl) propyl methacrylate (MPS) was used for the uniform dispersion of nanoparticles. Two micro-rotors were easily operated using external magnets, which provided 
a breakthrough for the fabrication and remote control of components inside microchannels for microfluidic applications.

However, this process may cause complexity in the synthesis of a ferromagnetic photocurable resin or may cause extra issues during the polymerization. As a magnetic nanoparticle could not be maintained for a long fabrication time, the stability and homogeneous dispersion of nanoparticles in a photocurable resin should be considered for material preparation. In addition, the surfaces of structures manufactured using ferromagnetic photocurable resins have a relatively higher roughness than structures processed with photocurable resins without magnetic particles. This can cause low resolution and unexpected disturbances under external forces. By using an appropriate solvent, it is possible to overcome these limitations through the uniform dispersion and stabilization of nanoparticles.

Instead of preparing a ferrofluidic photocurable resin by mixing magnetic materials into a photocurable resin, there is another method of imparting a magnetic function: magnetically coating the outer surface after the 3D structure's fabrication using a deposition method. In the initial form of a magnetic-driven actuator, a simple porous structure can be coated with a nickel/titanium (Ni/Ti) bimetallic layer as a magnetic material to induce actuation in a magnetic field for a targeted cell transportation system or a drug delivery system [65]. Cylindrical and hexahedral micro-robots can be manipulated by an external magnetic field gradient in the $x$-direction when they are aligned with the $z$-axis. This simple porous structure can be expanded into a complicated 3D shape like, a helical structure. Ding et al. coated an Ni/Ti bimetallic layer onto an ABF structure using e-beam evaporation, thereby giving magnetic properties to a structure for remote control [64]. They encapsulated an ABF inside a droplet using a flow-focused droplet generator, and they remotely manipulated the cells and droplets within the microfluidic system with an external magnetic field, thereby suggesting the possibility of expansion to microfluidic system applications. The effect of an anisotropic magnetic shape on ABF structures under magnetic fields has been studied $[50,66]$. It has been found that as the helix angle of a structure becomes smaller, the angle between the external magnetic field and the axis of the ABF structure tends to decrease, and a higher magnetic field frequency allows for a smaller angle between the axes of the $\mathrm{ABF}$ and rotation. To impart magnetic properties to a limited region, an $\mathrm{Ni} / \mathrm{Ti}$ bimetallic layer can be coated only onto a desired region using a sacrificial mask. Kim et al. fabricated a cilia-inspired micro-robot in which only the cilia parts were coated with an Ni/Ti bilayer, with the other parts remaining uncoated via the use of a sacrificial mask that blocked the coating and was removed after the end of the coating process [63] (Figure 2e-h). By mimicking a Paramecium, the cilia parts are actuated using non-reciprocal motion by applying an external magnetic field and generating a net propulsive force that enables the precise actuation of a cilia-inspired microactuator.

Considering the strength of TPP, the fabrication of complex functional microstructures with functions other than actuation by magnetic field is possible. There is no need for an additional assembly process to bond functional and actuation parts when using TPP and selective magnetic deposition for the targeted and triggered delivery of materials. A syringe-shaped micro-transporter was devised for the efficient delivery of drugs and therapeutic agents via a corkscrew motion [72]. This transporter is different from other actuators in that various tasks such as the loading, releasing, and transporting of agents can be achieved. A pumping mechanism based on Archimedes screw-pump was designed to load and unload materials according to capacity. Other passive and active suspensions could be transported inside a selective microfluidic system using this method. If this unique structure is used for bio-related applications, it is expected that it will be possible to reach a specific remote region (e.g., gastrointestinal tract) and deliver drugs to said target. It also able to perform more complicated tasks such as occlusions removal, the sampling of cells or tissues for diagnostic analysis, and local fluid flow generation for mixing. A micro-rotor that used Pd for catalyst absorption and $\mathrm{Fe}_{3} \mathrm{O}_{4}$ for deposition was utilized to treat acrylic-based structures was proposed [69] (Figure 2i,j). By grafting different types of materials, the fabrication of hybrid microactuators that can be driven by magnetic force and equipped with functionality can be achieved. A hybrid artificial bacterial flagellum (h-ABF) consisting of a ferromagnetic alloy head and a spiral polymer tail was fabricated, 
and it was found to have many advantages over all-metal structures. Because an h-ABF replaces metal parts with polypyrrole (PPy), it is lightweight and sedimentation reduction, navigation enhancement, and biocompatibility improvements [73]. A 3D cavity part can be filled with magnetic cobalt/nickel $(\mathrm{Co} / \mathrm{Ni})$ and biocompatible PPy by electrodeposition. An h-ABF is physically stable in an aqueous environment with a rigid connection between the metallic and polymeric segments. Swarm control can be performed by the wireless manipulation of the h-ABF with a rotating magnetic field. A capsule-type micro-robot consisting of a cap and a plunger was fabricated to deliver drugs or cells to a targeted region [3]. Only the plunger part was magnetic, and it was confirmed that actuation was possible under an external magnetic field. Drugs or cells can be encapsulated in a container before being transported to a target location in vitro via corkscrewing and "pick-and-drop" (P and D) motions. Porous-shaped actuators with bigger capacities and porous niche-shaped structures have also been proposed. Cylindrical and hexahedral-shaped 3D micro-niche actuators were fabricated and then coated with $\mathrm{Ni} / \mathrm{Ti}$ bilayers for the culture and transportation of cells to a targeted position under magnetic field gradients [65]. The cylindrical-shaped micromachine showed a higher moving speed compared to that of the hexahedral-shaped actuator. As a biocompatible magnetic-driven actuator, hydrogel-based biodegradable micro-swimmers have been fabricated by TPP [74]. This structure can facilitate promising biomedical applications in fields such as biology, medicine, drug delivery, and diagnostics. The micro-swimmer, which is composed of four rigid segments that are each connected to the next segment by springs, was found to be able to return to its initial state after disturbance, thereby maintaining strong structural robustness. This micro-swimmer was able to achieve undulatory locomotion along with the directions guided by an external magnetic field in a low Reynolds number regime, and the swimming direction of the micro-swimmer was well-controlled.

In addition, when fabricating a magnetic-driven actuator/robot for remote control, it is possible to produce an actuator capable of real-time tracking. A micro-actuator can colored after printing for tracking purposes, but multiple functionalization steps are required using the general method, and there is are limitation factors such as quenching that cause the color to decrease over time [75]. It is possible to fabricate a one-step, magnetic-driven, helical micro-actuator using TPP, and this structure can include structural colors by adding arrays of blocks with dimensions of approximately $1 \mu \mathrm{m}$ or less on the flat surface of the head part [76]. A metallic or dielectric material is coated onto a patterned surface for a distinct color response under visible light, and it provides a permanent and qualitative method for visually locating and identifying actuators when driven under a magnetic field. The real-time tracking of a rotating helical actuator at a low frequency is possible based on a color change with an angular orientation with respect to a light source, and rotational angular changes in horizontal and vertical planes can be detected and quantitatively identified by observing the expressed colors.

Despite its various strengths, magnetically-manipulated fabrication has many requirements that must be considered in order to make efficient structures. The consideration of mechanical strength is essential in fabricating 3D magnetic structures using ferrofluidic photoresists [68]. A structure with a low mechanical strength cannot achieve a desired performance in harsh environments such as viscous and narrow-gap conditions. Hybrid micro-actuators/robots have shown excellent performance in remote operation while maintaining high mechanical performance. A nickel and phosphorus (Ni-P) alloy has the advantages of a high hardness, wear/corrosion resistance, and good magnetic sensitivity [70] (Figure 2k,1). An Ni-P composite was introduced into a micro-actuator/robot using an electroless plating process, and it not only allowed for the movement of the robot to be remotely controlled but also gave a favorable mechanical performance. In addition, a modification to structural strength and recovery can be induced through the diversification of coatings method, resulting in the expansion of the functionalization of the structure. A hybrid structure with a thin alumina layer on the outer surface by atomic layer deposition (ALD) was shown to have better mechanical strength and recoverability than that without alumna coating [77]. By removing the backbone of the polymer after the ALD process, a hollow metallic structure with high strength and ductility but small size and 
weight can be obtained [78]. As the intensity of the magnetic field is considered relatively low and biologically harmless, the remote control of a micro-actuator using a magnetic field has been regarded as a good candidate in bio-related fields among various actuation methods. However, regarding $\mathrm{Ni} / \mathrm{Ti}$ bilayer coatings, $\mathrm{Ni}$ is harmful heavy metal to living organisms, and biocompatibility issues may arise. Therefore, the treatment of biocompatible alternatives (e.g., ones that are biodegradable or bioresorbable) is still in demand for in vivo applications.

\subsection{Optically Manipulated Micro-Actuator/Robot}

In addition to micro-actuator/robot actuation by an external chemical environment and magnetic field, the optical manipulation of micro-actuators/robots has been studied (Table 1). As a focused laser beam is irradiated onto an object, an optical force is generated in the momentum exchange between light and matter by the law of momentum conservation [79]. By making use of the light-matter interaction, optical forces can be used to trap, move, and rotate microstructures [80], and they have been successfully used in a variety of applications in physics, chemistry, and biology [81]. As the representative optical manipulation of micro-actuators/robots, optical tweezers are created from an electric field gradient provided by a highly focused laser beam, which allows objects of various sizes ranging from several nanometers to tens of micrometers to be moved and controlled in a non-contact, frictionless, and precise manner. For single-beam trapping, optical trapping regimes depend on the particle's size, thus affecting light wavelength. If an object is much smaller than the wavelength of the laser beam, it is usually called the Rayleigh regime, and an electromagnetic model could be used to better understand the trapping mechanism. This regime is regarded as a point dipole to satisfy Rayleigh scattering. In contrast, if an object is larger than the wavelength of the laser, it is referred to as Ray optics or geometric optics regimes. In this case, trapping force is independent of particle size. If the object size is compatible with the wavelength of the laser, the Mie scattering theory helps to bridge the gap between the two regions [82-84].

Table 1. Characteristics of actuation method of micro-actuator/robot.

\begin{tabular}{|c|c|c|c|c|}
\hline & Catalytic & Magnetic & Optical & Acoustic \\
\hline Strength & $\begin{array}{l}\text { Simple fabrication. } \\
\text { Speed control. } \\
\text { High speed motility. } \\
\text { No need for } \\
\text { complex/bulky } \\
\text { devices. }\end{array}$ & $\begin{array}{l}\text { Speed control. } \\
\text { Direction control. } \\
\text { Applicability in vivo. } \\
\text { Precise manipulation. } \\
\text { Various movements. }^{1} \\
\text { Real-time tracking. }^{\text {. }}\end{array}$ & $\begin{array}{c}\text { Speed control. } \\
\text { Direction control. } \\
\text { Precise manipulation. } \\
\text { Various movements. }^{1} \\
\text { Remote control }^{2} \\
\text { hard-to-reach areas. }^{2} \\
\text { Biocompatibility. } \\
\text { Real-time tracking. }\end{array}$ & $\begin{array}{l}\text { Simple fabrication. } \\
\text { Speed control. } \\
\text { High speed motility. } \\
\text { Applicability in vivo. }\end{array}$ \\
\hline $\begin{array}{l}\text { Limitation } \\
\text { and Requirement }\end{array}$ & $\begin{array}{c}\text { Low directional } \\
\text { control. } \\
\text { Low biocompatibility. }\end{array}$ & $\begin{array}{c}\text { Limitation of materials. }^{3} \\
\text { Low stability in fabrication. } \\
\text { Biocompatibility issue (Ni/Ti coating). } \\
\text { Low mechanical strength. } \\
\text { Requirements: } \\
\text { homogeneous } \\
\text { dispersion of the } \\
\text { material and } \\
\text { bulky operating } \\
\text { system. }\end{array}$ & $\begin{array}{l}\text { Difficulty in applicability } \\
\text { in vivo due to lower } \\
\text { optical transparency. } \\
\text { Requirements: } \\
\text { optical transparency and } \\
\text { complicate optical } \\
\text { systems. }\end{array}$ & $\begin{array}{l}\text { Low directional control. } \\
\text { Weak performance that } \\
\text { comes from the TPP } \\
\text { characteristic. } 5 \\
\text { Requirements: } \\
\text { complicated } \\
\text { acoustic system. }\end{array}$ \\
\hline Applications & Material transport [58]. & $\begin{array}{c}\text { Material transport }[60,63,72] . \\
\text { Micro-turbine [69], rotor }[70] \text {, etc. }\end{array}$ & $\begin{array}{l}\text { Micro-turbine, rotor, } \\
\text { and actuator [85-90]. }\end{array}$ & Actuator [91]. \\
\hline
\end{tabular}

Kawata et al. used laser trapping force to realize the sophisticated operation of micro-oscillators such as the capture of beads, spring pulling, and displacement release [88]. Optical trapping provides an opportunity for the ultra-precise manipulation of micro-actuators/robots fabricated by TPP [92,93]. 
When an object trapped in a laser beam has a distinctive shape such as helical, the object tends to rotate due to optical torque derived from the light itself. The light carries both linear and angular momentum, and trapped objects can rotate through interaction with light due to the transmission of angular momentum. It has been proven through many studies that various movements (e.g., translation, rotation, sliding, and swing) of micro-actuators/robots are possible using optical tweezers [85-88,94]. For example, a micro-rotor was fabricated through TPP, and it could be optically manipulated using optical tweezers. The optical tweezers exerted flux for rotation, as well as a collecting force to trap the micro-rotor. In Maruo's research, a micro-gear was kept untethered after fabrication, while the shaft was connected to the substrate, and a continuous laser was not required to keep the structure to a fixed position [95]. The rotational motion of the gear was achieved by trapping a tooth of the micro-gear with optical tweezers and making the laser beam have a controllable circular path. A microstructure with a metalized surface using electroless plating was driven with ultralow-power due to ablation and repulsive force with the substrate [86] (Figure 3b-d). The net repulsive force exerted on a metallic surface of micro-rotor blades is larger than the attractive force applied to a dielectric micro-rotor. A metalized micro-rotor can be driven efficiently by optimizing the radiation pressure exerted on the tilted blade and topology of the blades. This micro-rotor is expected to have a wide range of applications due to its low energy consumption, high performance, and ability to be grafted to a lab-on-a-chip. Galajda and Ormos succeeded in tweezing and rotating a micro-rotor using an optical tweezer [96]. They found that the amount of rotational momentum depended on where the micro-rotor was focused, and the rotational speed depended on the light scattering. In addition, the shape of the micro-rotor affected efficiency, and the efficiency of the sprinkler-shaped micromachine exceeded that of helical and propeller-shaped micro-rotors. A turbine-like symmetrical micro-rotor was driven using a spiral phase plate (SPP) [87] (Figure 3e,f). Using an SPP, a plane wave was converted into a helical wave that carried orbital angular momentum while giving the SPP an inverse angular momentum that could exert a torque to actuate a rotation of the SPP and induce symmetrical micro-rotor rotation. Under an optical tweezer system, a micro-actuator/robot not only stabilizes to a fixed position but also generates high torque when non-absorbing and non-spherical micro-actuators/robots are incorporated by the orbital angular momentum into a Gaussian laser beam. By integrating the TPP technique with temperature-responsive materials, the fabrication of a structure that responds to stimuli differently depending on the amount of light is possible. Hippler et al. fabricated a 3D hetero-microstructure using poly(N-isopropyl acrylamide) (pNIPAM) that exhibited a substantial response to changes in temperature close to its low critical solution temperature [97]. During the laser direct writing process, it was found that the material parameters could be changed on-demand in a single resist formulation through the variation of the local exposure dose, and a sophisticated 3D architecture with a large amplitude and complex response under light exposure was fabricated. Zheng et al. successfully fabricated a 3D Near-infrared (NIR) light-driven hydrogel micro-actuator with a fast response using TPP and macroscopic pNIPAM/nano-Fe ${ }_{3} \mathrm{O}_{4}$ hydrogels. This micro-actuator showed fast (response time $\approx 0.033 \mathrm{~s}$ ) and reversible responses that could "close" or "open" in response to light. By changing the laser focus and power, the distance between the two arms of the micro-actuator could also be controlled. Moreover, photoreactive hydrogel micro-actuators can have numerous potential uses in biomedical applications due to their biocompatibility. Considering that $\mathrm{Fe}_{3} \mathrm{O}_{4}$ nanoparticles can also work magnetically, this actuator can be expected to operate under optical and magnetic control systems [98]. 


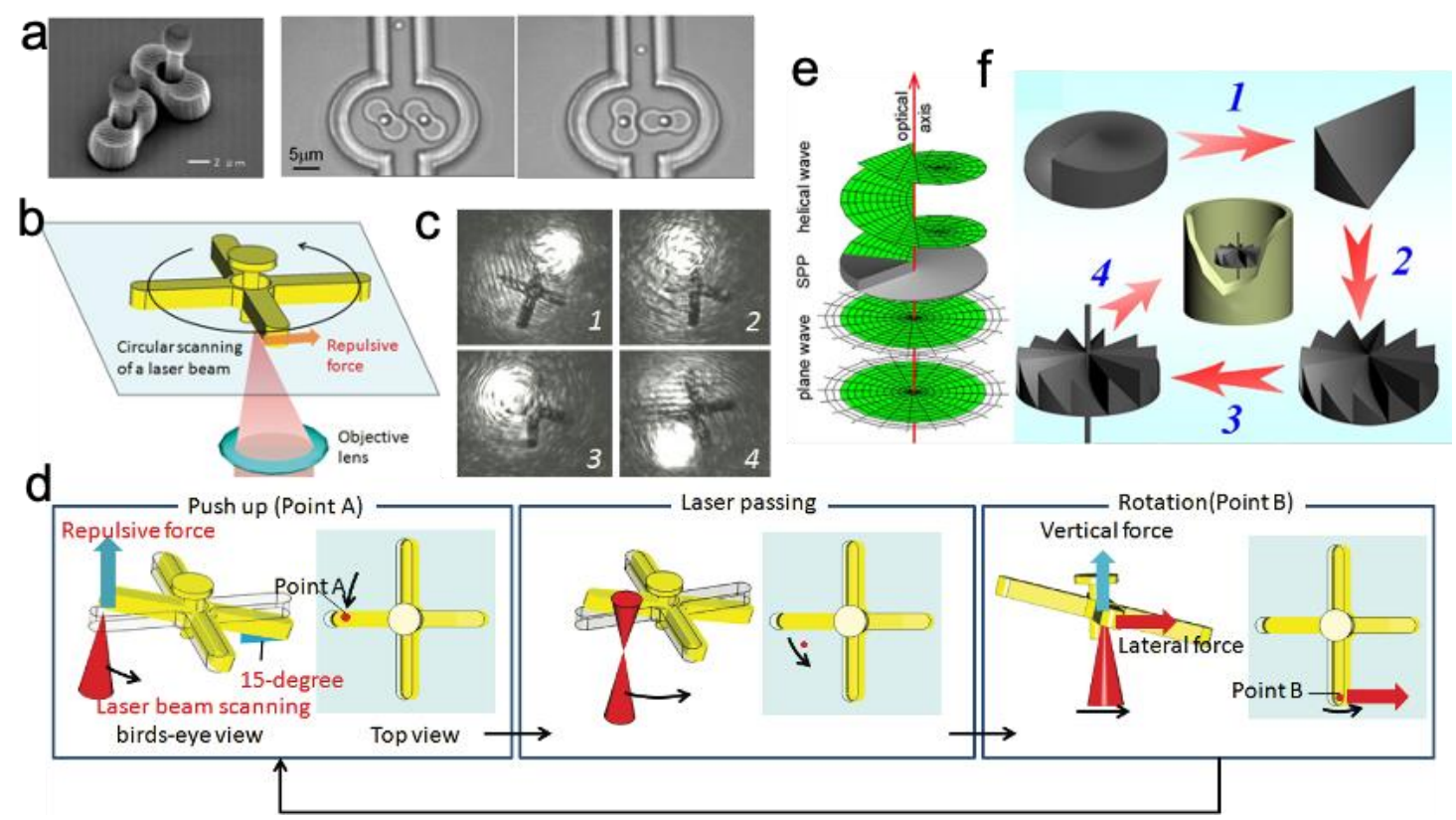

Figure 3. Optically manipulated micro-actuators/robots. (a) SEM image of the lobed micropump and images of optically driven micro-pump [85] (reproduced from [85] with permission from American Institute of Physics (AIP) Publishing); (b) schematic of optical driving of a metallized micro-rotor [86]; (c) sequential optical images of a rotating micro-rotor (scale bar: $10 \mu \mathrm{m}$ ) [86]; (d) schematic of driving mechanism of a metallized micro-rotor with repulsive force [86] (reproduced from [86] with permission from Japan Laser Processing Society); (e) schematic of mechanism of a spiral phase plate (SPP) converting a plane wave into a helical wave [87]; (f) design of a turbine-like micro-rotor [87] (reproduced from [87] with permission from AIP Publishing).

Microstructures of various shapes can be used in microfluidic applications such as microscale pumps and mixers. A micro-pump was fabricated based on the generation of net flow using two-lobed micro-rotors and dual optical tweezers [85] (Figure 3a). The net flow rate is proportional to the rotational speed of a micro-rotor, and this proportion was utilized through a micro-pump by trapping a micro-screw using optical tweezers and rotating a blade connected to a micro-screw, which served as a microscale mixer [94]. The screws with smaller pitches and thinner blades, as well as optical tweezers with larger numerical apertures, contributed to the increase in rotational speed. Two chiral propellers were fabricated, and these counter-spinning propellers were trapped by holographic optical trapping [89]. Hydrodynamic synchronization, a fundamental physical phenomenon by which self-sustained oscillators interact through perturbations in the surrounding fluid and converge to a stable synchronized state, was achieved by precisely controlling the relative torque of the two propellers. The precise fabrication of microfluidic components by TPP and the precise flow control of the precisely fabricated structure by optical control were simultaneously achieved as well.

A combination of micro-optic components (e.g., waveguide, diffractive, and holography) and actuating parts makes it possible to control the micro-optical component and precisely manipulate the actuating part. A free-standing waveguide fabricated using TPP can be manipulated in any direction, thus making it possible to transmit/receive light in a region that is difficult to reach [99]. By incorporating an optical waveguide into an adjacent micro-rotor, and optical fiber can be coupled to the waveguide and a micro-rotor could be controlled with precision [90]. The precise manipulation of a micro-actuator/robot is also possible via the optical control of microscopic diffractive optical elements. Furthermore, combining optical tweezers with digital holography makes it possible to create a large number of high-quality optical traps, and it is expected that the real-time 3D manipulation of multiple objects at the same time will soon be possible [100-102]. 
The control of a micro-actuator/robot's motion using optical force has many strengths, but some considerations must be considered during its application. Optical transparency is required to manipulate a micro-actuator/robot using optical controls such as optical tweezers [82,103]. Generally, objects involved in vivo applications exhibit a lower optical transmittance, and the application area can be limited in bio-related applications such as biomaterials or prototyping tests. If a transparent structure can be fabricated using a novel photocurable resin with the steady development of photoresists, the scope of the applications of micro-actuator/robot motion control using optics will be broadened. Additionally, the optical force manipulation of large objects in a liquid medium can suffer from high drag, during the dynamic effect of optical force is much less pronounced. These limitations can be improved through the continuous development of optical drives such as plasmon-enhanced forces [82,104]. Nishiguchi et al. fabricated a stimulus-responsive nanocomposite/hydrogel actuator with a defined 3D geometry using programmed printing density via TPP. This structure showed ultrafast/reversible shape morphing through plasmon heating. The dynamic-static bilayer helices of PNIPAm-Au nanorods nanocomposite gels were fabricated using a newly synthesized PNIPAm macro-crosslinker. Light-driven manipulation induced ultrafast/reversible shape changes based on body deformation. The dynamic control of the large amplitude of actuation was performed through plasmonic heating [104].

\subsection{Acoustically Manipulated Micro-Actuator/Robot}

In addition to magnetic and optical control, acoustic-based actuation has its own unique advantages and is considered a promising method in that it can be applied in various areas due to its non-invasive/non-contact nature. However, the development of micro-actuator/robot motion control using acoustics remains in its infancy, and a small number of studies have been performed. A study on acoustically actuating a polydimethylsiloxane (PDMS) polymeric micro-rotor fabricated using conventional lithography was conducted [105]. The acoustic streaming flow was generated by acoustically oscillating the sharp-edge structures of a pre-defined polymeric micro-rotor, and the rotation of the micro-rotor was achieved. This showed the idea that an acoustic micro-actuator/robot offers great potential for diverse fields such as microfluidic applications and targeted material delivery.

Attempts have been made to apply this principle to actuators processed through TPP. Bertin et al. were able to generate non-contact acoustic propulsion from armed micro-bubbles that could last for several hours under forced oscillations and had a range of 10-20 $\mu \mathrm{m}$ [91] (Figure 4). An armed micro-bubble (AMB)-based micro structure mounted on a solid pedestal countering bubble buoyancy was fabricated using direct laser writing. Then, the shell-shaped structure was placed into a PDMS cell filled with $\mathrm{NaCl}$ water solution containing $2 \mu \mathrm{m}$ spherical particles to observe the stream line. The acoustic resonance of the AMBs was determined by capillary force, not by gas volume, and the micro-swimmer showed good motility and moving speed. AMBs are expected to be promising for self-moving microscale objects via acoustic force as basic elements for controlled active assembly that are ultimately for mixing and transport applications. 

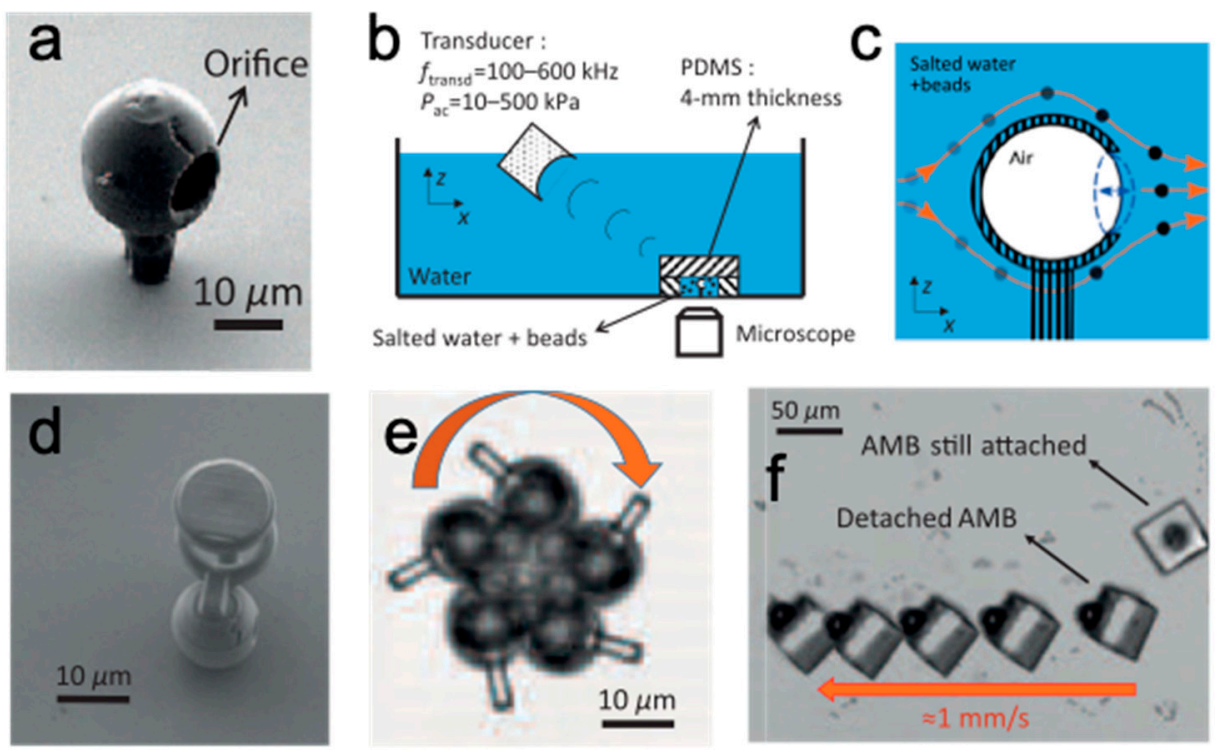

Figure 4. Acoustically manipulated micro-actuators/robots. (a) SEM image of the device; (b) experimental setup for acoustic manipulation; (c) schematic of the bubble-first vibration mode; (d) SEM image of fabricated spinner; (e) image of armed micro-bubble (AMB) spinning at $175 \mathrm{~Hz}$; and (f) image of moving AMB [91] (reproduced from [91] with permission from American Physical Society).

\section{Perspectives}

Due to rapid technological progress, research is currently being conducted under ideal conditions, and it is necessary to study motion control in environments similar to actual environments. For example, to realize an actuator that operates in vivo, further studies on the actuation of micro-actuators in artificial microfluidic chips with high viscosity and flow are needed in order to properly prepare for real-life applications. Another new approach suggests the possibility of solving issues that may arise in existing actuation through multi-material TPP processing [106]. Multi-material-based actuators utilizing materials ranging from hard to soft/elastic materials are able to move in complex environments. Actuators/robots that are operated at larger scales by utilizing both soft and rigid materials can improve performance, handle uncertainty, and reduce control requirements, thus enabling efficient actuator movement in real environments. Micro-actuators/robots with soft materials that are combined with rigid materials can facilitate large movements in narrow spaces due to increased compliance $[107,108]$. Hence, the concept of multi-material-based fabrication for a diverse range of materials has shown potential for the improvement of robot functionality and complexity. It is expected that 3D multi-material micro-actuators can ultimately move closer to the complexity found in living organisms at the same size scales. The use of multiple materials with a wide range of moduli can create complex mechanisms in small quantities. More complex designs are possible by increasing the number of printing steps, and they can be expanded according to the number of materials instead of the number of alternating layers due to the ability to print inside existing structures $[107,109,110]$. Hence, the fabrication of 3D multi-material-based micro-actuators is still challenging because it requires multiple steps in addition to the general fabrication method.

However, TPP makes it possible to overcome this limitation because its structure fabrication is based on laser-direct writing. In previous studies, this method was used to fabricate artificial scaffolds for cell culture and printing [111,112] and to induce local mechanical/chemical property changes by controlling the degree of crosslinking of different proteins on hydrogels, which leads to cell adhesion and differentiation on TPP-fabricated scaffolds [113-115]. As an example applied to an actuator, Soreni-Harari et al. printed two materials with three orders of difference of Young's modulus in a consecutive cycle using the TPP technique [106]. They fabricated a high-strength adhered hybrid structure with a layer accuracy of less than three microns by integrating a rigid material 
and a soft elastic material, ultimately making a structure capable of more than $200 \%$ deformation. The fabrication of a 3D-printed, 2-mm wingspan flapping wing with a large deformation potential was possible using a multilink multi-material mechanism. Sun's group developed femtosecond, laser-programmed, 3D, micro, artificial musculoskeletal system robot fabrication composed of multiple materials [116]. This structure was made by two materials of different stiffness values-SU-8 (stiffer) as a skeleton and a pH-responsive BSA (bovine serum albumin) protein (softer) as a smart muscle. The successive on-chip TPP strategy enabled the sequential fabrication of two photosensitive materials within a predesigned configuration. A pH-responsive spider micro-robot and a 3D smart microgripper that enabled controllable grabbing and releasing were fabricated through the successive on-chip TPP strategy.

For the efficient processing and operation of micro-machines processed with TPP, new material integration requires the consideration of issues such as fabrication compatibility, development and post-processing, cross-interaction, and interface issues.

\section{Conclusions}

TPP is in the spotlight as a new field of micro/nanofabrication processes in that it enables the fabrication of precise and complicated structures with a high spatial resolution and a flexible design. Much effort has been made to develop and improve innovative micro-actuators/robots that can be remotely driven. To impart a specific function to a micro-actuator/robot, structural and material modifications can be performed. Various types of micro-actuators (e.g., transporter, mixer, pump, rotor, and swimmer) have been fabricated using TPP, and efficient activation is possible when using diverse driving methods such as chemical, magnetic, optic, and acoustic forces.

First of all, a catalytic micro-tubular actuator converts chemical energy into mechanical energy for jet propulsion. However, the commonly used rolled-up method is not able to make an asymmetric tubular microstructure [8,9,54-57], and this can be resolved by laser-direct writing (LDW) processes like TPP. A rocket-shaped asymmetric micro-tubular actuator was found to possesses successful dynamic motion generation through the chemical decomposition of an external chemical, resulting in actuation with a high speed [58].

In addition to chemically catalytic actuation, the remote control of a microscale actuator/robot can be achieved using magnetic, optical, and acoustic manipulation. To manipulate a micro-actuator/robot using a magnetic force, magnetic nanoparticles (e.g., $\mathrm{Fe}_{3} \mathrm{O}_{4}$ ) can be added to a photocurable resin in order to control the movement of a 3D microscale structure (e.g., microturbine, micro-rotor, and actuator) via an external magnetic field [60-62,66-68]. However, this material has issues including its stability, homogeneous dispersion during long fabrication processes, and scattering during the processing. In another way, by imparting ferromagnetic properties to a microstructure is possible when using an Ni/Ti bilayer coating, which is the most widely used structural treatment for magnetic manipulation [63-65]. However, $\mathrm{Ni}$ is generally regarded as inappropriate to be applied to bio-related applications due to its non-biocompatibility, and it should also be considered that a bulky operating system is required for magnetic manipulation.

When adjusting a micro-actuator using optical manipulation, unlike magnetic manipulation, no additional treatment is required. It is possible to successfully and optically control an actuator's movement in a non-contact/non-invasive manner, and the actuator, pump, and mixer can be grafted into a microfluidic system [85-88]. In addition, it is able to fabricate other optical components (e.g., waveguide) near an actuator by making use of the advantages of TPP, thus making the efficient actuation and control of a micro-actuator possible [90]. However, this requires the optical transparency of a structure, so the range of applications is limited. Therefore, the development of a photocurable resin that could fabricate a transparent feature is required, and it is also critical to consider the enormous cost and effort, due to complicated optical systems, that is required for optics-based manipulation.

The acoustic-based actuation of a micro-actuator is considered to be promising technology due to its non-invasive and contactless nature [91]. However, due to the weak mechanical connection between 
voxels, it has limited operation capabilities under an acoustic field. Though critical challenges have remained for stable manipulation under acoustic forces, it is expected that potential applications will be broadened by solving issues such as the reinforcement of mechanical strength.

Though there are still issues to be resolved for the efficient manipulation of a micro-actuator. However, due to the merits of 3D precision processing including efficient actuation and control through functionalization, TPP-based micro-actuators will soon be established as next-generation, highly efficient, and ultra-precise actuators. TPP can be applied in a wide range of fields including micro-robotics, biomedical engineering, and regenerative medicine.

Funding: This work has supported by the National Research Foundation of Korea (NRF) grant funded by the Korea government (MSIT) (NRF-2018R1C1B6008332), and the Incheon National University Research Grant in 2017.

Conflicts of Interest: The author declare no conflict of interest.

\section{References}

1. Li, H.; Go, G.; Ko, S.Y.; Park, J.-O.; Park, S. Magnetic actuated pH-responsive hydrogel-based soft micro-robot for targeted drug delivery. Smart Mater. Struct. 2016, 25, 027001. [CrossRef]

2. Fox, C.B.; Cao, Y.; Nemeth, C.L.; Chirra, H.D.; Chevalier, R.W.; Xu, A.M.; Melosh, N.A.; Desai, T.A. Fabrication of Sealed Nanostraw Microdevices for Oral Drug Delivery. ACS Nano 2016, 10, 5873-5881. [CrossRef]

3. Lee, S.; Kim, S.; Kim, S.; Kim, J.Y.; Moon, C.; Nelson, B.J.; Choi, H. A Capsule-Type Microrobot with Pick-and-Drop Motion for Targeted Drug and Cell Delivery. Adv. Healthc. Mater. 2018, 7, e1700985. [CrossRef]

4. Maziz, A.; Plesse, C.; Soyer, C.; Chevrot, C.; Teyssié, D.; Cattan, E.; Vidal, F. Demonstrating kHz Frequency Actuation for Conducting Polymer Microactuators. Adv. Funct. Mater. 2014, 24, 4851-4859. [CrossRef]

5. Truby, R.L.; Wehner, M.; Grosskopf, A.K.; Vogt, D.M.; Uzel, S.G.M.; Wood, R.J.; Lewis, J.A. Soft Somatosensitive Actuators via Embedded 3D Printing. Adv. Mater. 2018, 30, 1706383-1706388. [CrossRef]

6. Villoslada, A.; Flores, A.; Copaci, D.; Blanco, D.; Moreno, L. High-displacement flexible Shape Memory Alloy actuator for soft wearable robots. Robot. Auton. Syst. 2015, 73, 91-101. [CrossRef]

7. Kim, H.; Lee, H.; Ha, I.; Jung, J.; Won, P.; Cho, H.; Yeo, J.; Hong, S.; Han, S.; Kwon, J.; et al. Biomimetic Color Changing Anisotropic Soft Actuators with Integrated Metal Nanowire Percolation Network Transparent Heaters for Soft Robotics. Adv. Funct. Mater. 2018, 28, 1801847-1801848. [CrossRef]

8. Mei, Y.; Solovev, A.A.; Sanchez, S.; Schmidt, O.G. Rolled-up nanotech on polymers: From basic perception to self-propelled catalytic microengines. Chem. Soc. Rev. 2011, 40, 2109-2119. [CrossRef]

9. Solovev, A.A.; Xi, W.; Gracias, D.H.; Harazim, S.M.; Deneke, C.; Sánchez, S.; Schmidt, O.G. Self-propelled nanotools. ACS Nano 2012, 6, 1751-1756. [CrossRef]

10. Gao, W.; Sattayasamitsathit, S.; Wang, J. Catalytically propelled micro-/nanomotors: How fast can they move? Chem. Rec. 2011, 12, 224-231. [CrossRef]

11. Sengupta, S.; Patra, D.; Ortiz-Rivera, I.; Agrawal, A.; Shklyaev, S.; Dey, K.K.; Cordova-Figueroa, U.; Mallouk, T.E.; Sen, A. Self-powered enzyme micropumps. Nat. Chem. 2014, 6, 415-422. [CrossRef]

12. Ma, X.; Wang, X.; Hahn, K.; Sanchez, S. Motion Control of Urea-Powered Biocompatible Hollow Microcapsules. ACS Nano 2016, 10, 3597-3605. [CrossRef]

13. Li, T.; Li, J.; Zhang, H.; Chang, X.; Song, W.; Hu, Y.; Shao, G.; Sandraz, E.; Zhang, G.; Li, L.; et al. Magnetically Propelled Fish-Like Nanoswimmers. Small 2016, 12, 6098-6105. [CrossRef]

14. Xu, T.; Yu, J.; Yan, X.; Choi, H.; Zhang, L. Magnetic Actuation Based Motion Control for Microrobots: An Overview. Micromachines 2015, 6, 1346-1364. [CrossRef]

15. Kirkham, G.R.; Britchford, E.; Upton, T.; Ware, J.; Gibson, G.M.; Devaud, Y.; Ehrbar, M.; Padgett, M.; Allen, S.; Buttery, L.D.; et al. Precision assembly of complex cellular microenvironments using holographic optical tweezers. Sci. Rep. 2015, 5, 8577. [CrossRef]

16. Yamaoka, Y.; Funatsu, K.; Yoshidumi, Y.; Kubo, A.; Notsuka, Y.; Takahashi, E. A compact scanning probe for photoacoustic microscopy using ultrasonic actuator stage. Jpn. J. Appl. Phys. 2020, 59, 030906. [CrossRef]

17. Larramendy, F.; Yoshida, S.; Maier, D.; Fekete, Z.; Takeuchi, S.; Paul, O. 3D arrays of microcages by two-photon lithography for spatial organization of living cells. Lab. Chip 2019, 19, 875-884. [CrossRef] 
18. Ushiba, S.; Shoji, S.; Masui, K.; Kuray, P.; Kono, J.; Kawata, S. 3D microfabrication of single-wall carbon nanotube/polymer composites by two-photon polymerization lithography. Carbon 2013, 59, 283-288. [CrossRef]

19. Puce, S.; Sciurti, E.; Rizzi, F.; Spagnolo, B.; Qualtieri, A.; De Vittorio, M.; Staufer, U. 3D-microfabrication by two-photon polymerization of an integrated sacrificial stencil mask. Micro Nano Eng. 2019, 2, 70-75. [CrossRef]

20. Lee, K.S.; Kim, R.H.; Yang, D.-Y.; Park, S.-H. Advances in 3D nano/microfabrication using two-photon initiated polymerization. Prog. Polym. Sci. 2008, 33, 631-681. [CrossRef]

21. Ovsianikov, A.; Gaidukeviciute, A.; Chichkov, B.N.; Oubaha, M.; MacCraith, B.D.; Sakellari, I.; Giakoumaki, A.; Gray, D.; Vamvakaki, M.; Farsari, M.; et al. Two-Photon Polymerization of Hybrid Sol-Gel Materials for Photonics Applications. Laser Chemistry 2008, 2008, 493059. [CrossRef]

22. Misawa, H.; Juodkazis, S. 3D Laser Microfabrication; Wiley-VCH: Weinheim, Germany, 2006. [CrossRef]

23. He, G.S.; Tan, L.-S.; Zheng, Q.; Prasad, P.N. Multiphoton Absorbing Materials: Molecular Designs, Characterizations, and Applications. Chem. Rev. 2008, 108, 1245-1330. [CrossRef]

24. Kogej, T.; Beljonne, D.; Meyers, F.; Physics, J.W.P.C. Mechanisms for enhancement of two-photon absorption in donor-acceptor conjugated chromophores. Chem. Phys. Lett. 1998, 298, 1-6. [CrossRef]

25. He, G.S.; Xu, G.C.; Prasad, P.N.; Reinhardt, B.A.; Bhatt, J.C.; Dillard, A.G. Two-photon absorption and optical-limiting properties of novel organic compounds. Opt. Lett. 1995, 20, 435-437. [CrossRef]

26. Infuehr, R.; Pucher, N.; Heller, C.; Lichtenegger, H.; Liska, R.; Schmidt, V.; Kuna, L.; Haase, A.; Stampfl, J. Functional polymers by two-photon 3D lithography. Appl. Surf. Sci. 2007, 254, 836-840. [CrossRef]

27. Malinauskas, M.; Žukauskas, A.; Bickauskaite, G.; Gadonas, R.; Juodkazis, S. Mechanisms of three-dimensional structuring of photo-polymers by tightly focussed femtosecond laser pulses. Opt. Express 2010, 18, 10209-10221. [CrossRef]

28. Lee, K.-S.; Kim, R.H.; Prabhakaran, P.; Yang, D.-Y.; Lim, T.W.; Park, S.H. Two-Photon Stereolithography. J. Nonlinear Opt. Phys. Mater. 2012, 16, 59-73. [CrossRef]

29. Zhou, X.; Hou, Y.; Lin, J. A review on the processing accuracy of two-photon polymerization. AIP Adv. 2015, 5, 030701-030723. [CrossRef]

30. Choi, J.; Koo, S.; Sakellari, I.; Kim, H.; Su, Z.; Carter, K.R.; Farsari, M.; Grigoropoulos, C.P.; Russell, T.P. Guided Assembly of Block Copolymers in Three-Dimensional Woodpile Scaffolds. ACS Appl. Mater. Interfaces 2018, 10, 42933-42940. [CrossRef]

31. Liu, Q.; Vanmol, K.; Lycke, S.; Van Erps, J.; Vandenabeele, P.; Thienpont, H.; Ottevaere, H. SERS using two-photon polymerized nanostructures for mycotoxin detection. RSC Adv. 2020, 10, 14274-14282. [CrossRef]

32. Engelhardt, S.; Hoch, E.; Borchers, K.; Meyer, W.; Kruger, H.; Tovar, G.E.M.; Gillner, A. Fabrication of 2D protein microstructures and 3D polymer-protein hybrid microstructures by two-photon polymerization. Biofabrication 2011, 3. [CrossRef]

33. Malinauskas, M.; Danilevicius, P.; Juodkazis, S. Three-dimensional micro-/nano-structuring via direct write polymerization with picosecond laser pulses. Opt. Express 2011, 19, 5602-5610. [CrossRef]

34. Wang, I.; Bouriau, M.; Baldeck, P.L.; Martineau, C.; Andraud, C. Three-dimensional microfabrication by two-photon-initiated polymerization with a low-cost microlaser. Opt. Lett. 2002, 27, 1348-1350. [CrossRef]

35. Thiel, M.; Fischer, J.; von Freymann, G.; Wegener, M. Direct laser writing of three-dimensional submicron structures using a continuous-wave laser at $532 \mathrm{~nm}$. Appl. Phys. Lett. 2010, 97. [CrossRef]

36. Kowalski, B.A.; Scott, T.F.; Bowman, C.N.; Sullivan, A.C.; McLeod, R.R. Exceeding the Diffraction Limit with Single-Photon Photopolymerization and Photo-Induced Termination. In Proceedings of the SPIE-The International Society for Optical Engineering, San Diego, CA, USA, 10-14 August 2008.

37. Li, Q.K.; Cao, J.J.; Yu, Y.H.; Wang, L.; Sun, Y.L.; Chen, Q.D.; Sun, H.B. Fabrication of an anti-reflective microstructure on sapphire by femtosecond laser direct writing. Opt. Lett. 2017, 42, 543-546. [CrossRef]

38. Spadaccini, C.M. Future perspectives on materials for two-photon polymerization. In Three-Dimensional Microfabrication Using Two-Photon Polymerization; Elsevier: Amsterdam, The Netherlands, 2020; pp. 671-681. [CrossRef]

39. Rajamanickam, V.P.; Ferrara, L.; Toma, A.; Proietti Zaccaria, R.; Das, G.; Di Fabrizio, E.; Liberale, C. Suitable photo-resists for two-photon polymerization using femtosecond fiber lasers. Microelectron. Eng. 2014, 121, 135-138. [CrossRef] 
40. Ma, Z.; Koo, S.; Finnegan, M.A.; Loskill, P.; Huebsch, N.; Marks, N.C.; Conklin, B.R.; Grigoropoulos, C.P.; Healy, K.E. Three-dimensional filamentous human diseased cardiac tissue model. Biomaterials 2014, 35, 1367-1377. [CrossRef]

41. Bückmann, T.; Stenger, N.; Kadic, M.; Kaschke, J.; Frölich, A.; Kennerknecht, T.; Eberl, C.; Thiel, M.; Wegener, M. Tailored 3D Mechanical Metamaterials Made by Dip-in Direct-Laser-Writing Optical Lithography. Adv. Mater. 2012, 24, 2710-2714. [CrossRef]

42. Ma, Z.; Huebsch, N.; Koo, S.; Mandegar, M.A.; Siemons, B.; Boggess, S.; Conklin, B.R.; Grigoropoulos, C.P.; Healy, K.E. Contractile deficits in engineered cardiac microtissues as a result of MYBPC3 deficiency and mechanical overload. Nat. Biomed. Eng. 2018, 2, 955-967. [CrossRef]

43. Walia, R.; Chopra, K.N. An Exhaustive Analysis of the Characterization of Photopolymer Material (SZ2080) by Two-Photon Polymerization, Waves Moving in a Periodic Potential, and Two-Photon Absorption. MSF 2020, 1003, 165-172. [CrossRef]

44. Farsari, M.; Vamvakaki, M.; Chichkov, B.N. Multiphoton polymerization of hybrid materials. J. Opt. 2010, 12, 124001. [CrossRef]

45. Psycharakis, S.; Tosca, A.; Melissinaki, V.; Giakoumaki, A.; Ranella, A. Tailor-made three-dimensional hybrid scaffolds for cell cultures. Biomed. Mater. 2011, 6. [CrossRef]

46. Staudinger, U.; Zyla, G.; Krause, B.; Janke, A.; Fischer, D.; Esen, C.; Voit, B.; Ostendorf, A. Development of electrically conductive microstructures based on polymer/CNT nanocomposites via two-photon polymerization. Microelectron. Eng. 2017, 179, 48-55. [CrossRef]

47. Xiong, W.; Liu, Y.; Jiang, L.J.; Zhou, Y.S.; Li, D.W.; Jiang, L.; Silvain, J.F.; Lu, Y.F. Laser-Directed Assembly of Aligned Carbon Nanotubes in Three Dimensions for Multifunctional Device Fabrication. Adv. Mater. 2016, 28, 2002-2009. [CrossRef]

48. Ma, Z.-C.; Zhang, Y.-L.; Han, B.; Chen, Q.-D.; Sun, H.-B. Femtosecond-Laser Direct Writing of Metallic Micro/Nanostructures: From Fabrication Strategies to Future Applications. Small Methods 2018, 2, 1700413-1700420. [CrossRef]

49. Long, J.; Xiong, W.; Wei, C.; Lu, C.; Wang, R.; Deng, C.; Liu, H.; Fan, X.; Jiao, B.; Gao, S.; et al. Directional Assembly of ZnO Nanowires via Three-Dimensional Laser Direct Writing. Nano Lett. 2020, 20, 5159-5166. [CrossRef]

50. Xu, T.; Gao, W.; Xu, L.-P.; Zhang, X.; Wang, S. Fuel-Free Synthetic Micro-/Nanomachines. Adv. Mater. 2016, 29, 1603250. [CrossRef]

51. DiLuzio, W.R.; Turner, L.; Mayer, M.; Garstecki, P.; Weibel, D.B.; Berg, H.C.; Whitesides, G.M. Escherichia coli swim on the right-hand side. Nature 2005, 435, 1271-1274. [CrossRef]

52. Peyer, K.E.; Zhang, L.; Nelson, B.J. Bio-inspired magnetic swimming microrobots for biomedical applications. Nanoscale 2013, 5, 1259-1272. [CrossRef]

53. Nelson, B.J.; Kaliakatsos, I.K.; Abbott, J.J. Microrobots for minimally invasive medicine. Annu Rev. Biomed. Eng. 2010, 12, 55-85. [CrossRef]

54. Gao, W.; Sattayasamitsathit, S.; Orozco, J.; Wang, J. Highly Efficient Catalytic Microengines: Template Electrosynthesis of Polyaniline/Platinum Microtubes. J. Am. Chem. Soc. 2011, 133, 11862-11864. [CrossRef]

55. Xu, B.; Mei, Y. Tubular micro/nanoengines: Boost motility in a tiny world. Sci. Bull. 2017, 62, 525-527. [CrossRef]

56. Wang, H.; Moo, J.G.; Pumera, M. From Nanomotors to Micromotors: The Influence of the Size of an Autonomous Bubble-Propelled Device upon Its Motion. ACS Nano 2016, 10, 5041-5050. [CrossRef]

57. Pumera, H.W.; Pumera, M. Fabrication of Micro/Nanoscale Motors. Chem. Rev. 2015, 115, 8704-8735. [CrossRef]

58. Chen, Y.; Xu, B.; Mei, Y. Design and Fabrication of Tubular Micro/Nanomotors via 3D Laser Lithography. Chem. Asian J. 2019, 14, 2472-2478. [CrossRef]

59. Li, R.; Jin, D.; Pan, D.; Ji, S.; Xin, C.; Liu, G.; Fan, S.; Wu, H.; Li, J.; Hu, Y.; et al. Stimuli-Responsive Actuator Fabricated by Dynamic Asymmetric Femtosecond Bessel Beam for In Situ Particle and Cell Manipulation. ACS Nano 2020, 14, 5233-5242. [CrossRef]

60. Peters, C.; Hoop, M.; Pane, S.; Nelson, B.J.; Hierold, C. Degradable Magnetic Composites for Minimally Invasive Interventions: Device Fabrication, Targeted Drug Delivery, and Cytotoxicity Tests. Adv. Mater. 2016, 28, 533-538. [CrossRef] 
61. Xia, H.; Wang, J.; Tian, Y.; Chen, Q.D.; Du, X.B.; Zhang, Y.L.; He, Y.; Sun, H.B. Ferrofluids for fabrication of remotely controllable micro-nanomachines by two-photon polymerization. Adv. Mater. 2010, 22, 3204-3207. [CrossRef]

62. Wang, J.; Xia, H.; Xu, B.B.; Niu, L.G.; Wu, D.; Chen, Q.D.; Sun, H.B. Remote manipulation of micronanomachines containing magnetic nanoparticles. Opt. Lett. 2009, 34, 581-583. [CrossRef]

63. Kim, S.; Lee, S.; Lee, J.; Nelson, B.J.; Zhang, L.; Choi, H. Fabrication and Manipulation of Ciliary Microrobots with Non-reciprocal Magnetic Actuation. Sci. Rep. 2016, 6, 30713. [CrossRef]

64. Ding, Y.; Qiu, F.; Casadevall, I.S.X.; Chiu, F.W.Y.; Nelson, B.J.; deMello, A. Microfluidic-Based Droplet and Cell Manipulations Using Artificial Bacterial Flagella. Micromachines 2016, 7, 25. [CrossRef]

65. Kim, S.; Qiu, F.; Kim, S.; Ghanbari, A.; Moon, C.; Zhang, L.; Nelson, B.J.; Choi, H. Fabrication and characterization of magnetic microrobots for three-dimensional cell culture and targeted transportation. Adv. Mater. 2013, 25, 5863-5868. [CrossRef]

66. Tottori, S.; Zhang, L.; Qiu, F.; Krawczyk, K.K.; Franco-Obregon, A.; Nelson, B.J. Magnetic helical micromachines: Fabrication, controlled swimming, and cargo transport. Adv. Mater. 2012, 24, 811-816. [CrossRef]

67. Peters, C.; Costanza, V.; Pané, S.; Nelson, B.; Hierold, C. Superparamagnetic Hydrogels for Two-Photon Polymerization and Their Application for the Fabrication of Swimming Microrobots. In Proceedings of the 18th International Conference on Solid-State Sensors, Actuators and Microsystems, Anchorage, AK, USA, 21-25 June 2015; IEEE: Piscataway, NJ, USA, 2015; pp. 1-4. [CrossRef]

68. Suter, M.; Zhang, L.; Siringil, E.C.; Peters, C.; Luehmann, T.; Ergeneman, O.; Peyer, K.E.; Nelson, B.J.; Hierold, C. Superparamagnetic microrobots: Fabrication by two-photon polymerization and biocompatibility. Biomed. Microdevices 2013, 15, 997-1003. [CrossRef]

69. Zandrini, T.; Taniguchi, S.; Maruo, S. Magnetically Driven Micromachines Created by Two-Photon Microfabrication and Selective Electroless Magnetite Plating for Lab-on-a-Chip Applications. Micromachines 2017, 8, 35. [CrossRef]

70. Wang, W.-K.; Sun, Z.-B.; Zheng, M.-L.; Dong, X.-Z.; Zhao, Z.-S.; Duan, X.-M. Magnetic Nickel-Phosphorus/Polymer Composite and Remotely Driven Three-Dimensional Micromachine Fabricated by Nanoplating and Two-Photon Polymerization. J. Phys. Chem. C 2011, 115, 11275-11281. [CrossRef]

71. Tian, Y.; Lu, D.; Jiang, H.; Lin, X. Preparation of a novel ferrofluidic photoresist for two-photon photopolymerization technique. J. Magn. Magn. Mater. 2012, 324, 3291-3294. [CrossRef]

72. Huang, T.Y.; Sakar, M.S.; Mao, A.; Petruska, A.J.; Qiu, F.; Chen, X.B.; Kennedy, S.; Mooney, D.; Nelson, B.J. 3D Printed Microtransporters: Compound Micromachines for Spatiotemporally Controlled Delivery of Therapeutic Agents. Adv. Mater. 2015, 27, 6644-6650. [CrossRef]

73. Zeeshan, M.A.; Grisch, R.; Pellicer, E.; Sivaraman, K.M.; Peyer, K.E.; Sort, J.; Ozkale, B.; Sakar, M.S.; Nelson, B.J.; Pane, S. Hybrid helical magnetic microrobots obtained by 3D template-assisted electrodeposition. Small 2014, 10, 1284-1288. [CrossRef]

74. Sun, H.C.M.; Liao, P.; Wei, T.; Zhang, L.; Sun, D. Magnetically Powered Biodegradable Microswimmers. Micromachines 2020, 11, 404. [CrossRef]

75. Ceylan, H.; Yasa, I.C.; Sitti, M. 3D Chemical Patterning of Micromaterials for Encoded Functionality. Adv. Mater. 2017, 29. [CrossRef]

76. Koepele, C.A.; Guix, M.; Bi, C.; Adam, G.; Cappelleri, D.J. 3D-Printed Microrobots with Integrated Structural Color for Identification and Tracking. Adv. Intell. Syst. 2020, 2. [CrossRef]

77. Bauer, J.; Hengsbach, S.; Tesari, I.; Schwaiger, R.; Kraft, O. High-strength cellular ceramic composites with 3D microarchitecture. Proc. Natl. Acad. Sci. USA 2014, 111, 2453-2458. [CrossRef]

78. Meza, L.R.; Das, S.; Greer, J.R. Strong, lightweight, and recoverable three-dimensional ceramic nanolattices. Science 2014, 345, 1322-1326. [CrossRef]

79. Dholakia, K.; Reece, P. Optical micromanipulation takes hold. Nano Today 2006, 1, 18-27. [CrossRef]

80. Ashkin, A. Acceleration and Trapping of Particles by Radiation Pressure. Phys. Rev. Lett. 1970, $24,156-159$. [CrossRef]

81. Grier, D.G. A revolution in optical manipulation. Nature 2003, 424, 810-816. [CrossRef]

82. Neto, P.A.M.; Nussenzveig, H.M. Theory of optical tweezers. Europhys. Lett. 2000, 50, 702-708. [CrossRef]

83. Stilgoe, A.B.; Nieminen, T.A.; Knöener, G.; Heckenberg, N.R.; Rubinsztein-Dunlop, H. The effect of Mie resonances on trapping in optical tweezers. Opt. Express 2008, 16, 15039-15051. [CrossRef] 
84. Daly, M.; Sergides, M.; Nic Chormaic, S. Optical trapping and manipulation of micrometer and submicrometer particles. Laser Photonics Rev. 2015, 9, 309-329. [CrossRef]

85. Maruo, S.; Inoue, H. Optically driven micropump produced by three-dimensional two-photon microfabrication. Appl. Phys. Lett. 2006, 89. [CrossRef]

86. Ikegami, T.; Ozawa, R.; Stocker, M.P.; Monaco, K.; Fourkas, J.T.; Maruo, S. Development of Optically-Driven Metallic Microrotors Using Two-Photon Microfabrication. J. Laser Micro Nanoen. 2013, 8, 6-10. [CrossRef]

87. Lin, X.-F.; Hu, G.-Q.; Chen, Q.-D.; Niu, L.-G.; Li, Q.-S.; Ostendorf, A.; Sun, H.-B. A light-driven turbine-like micro-rotor and study on its light-to-mechanical power conversion efficiency. Appl. Phys. Lett. 2012, 101. [CrossRef]

88. Kawata, S.; Sun, H.B.; Tanaka, T.; Takada, K. Finer features for functional microdevices. Nature 2001, 412, 697-698. [CrossRef]

89. Di Leonardo, R.; Buzas, A.; Kelemen, L.; Vizsnyiczai, G.; Oroszi, L.; Ormos, P. Hydrodynamic synchronization of light driven microrotors. Phys. Rev. Lett. 2012, 109, 034104. [CrossRef]

90. Kelemen, L.; Valkai, S.; Ormos, P. Integrated optical motor. Appl. Opt. 2006, 45, 2777-2780. [CrossRef]

91. Bertin, N.; Spelman, T.A.; Stephan, O.; Gredy, L.; Bouriau, M.; Lauga, E.; Marmottant, P. Propulsion of Bubble-Based Acoustic Microswimmers. Phys. Rev. Appl. 2015, 4. [CrossRef]

92. Lehmuskero, A.; Johansson, P.; Rubinsztein-Dunlop, H.; Tong, L.; Käll, M. Laser Trapping of Colloidal Metal Nanoparticles. ACS Nano 2015, 9, 3453-3469. [CrossRef]

93. Palima, D.; Glückstad, J. Gearing up for optical microrobotics: Micromanipulation and actuation of synthetic microstructures by optical forces. Laser Photonics Rev. 2013, 7, 478-494. [CrossRef]

94. Lin, C.-L.; Lin, Y.-S.; Baldeck, P. Rotational Efficiency of Photo-Driven Archimedes Screws for Micropumps. Micromachines 2015, 6, 674-683. [CrossRef]

95. Maruo, S.; Ikuta, K.; Korogi, H. Force-controllable, optically driven micromachines fabricated by single-step two-photon microstereolithography. J. Microelectromech. Syst. 2003, 12, 533-539. [CrossRef]

96. Galajda, P.; Ormos, P. Rotors produced and driven in laser tweezers with reversed direction of rotation. Appl. Phys. Lett. 2002, 80, 4653-4655. [CrossRef]

97. Hippler, M.; Blasco, E.; Qu, J.; Tanaka, M.; Barner-Kowollik, C.; Wegener, M.; Bastmeyer, M. Controlling the shape of 3D microstructures by temperature and light. Nat. Commun. 2019, 10, 232. [CrossRef]

98. Zheng, C.; Jin, F.; Zhao, Y.; Zheng, M.; Liu, J.; Dong, X.; Xiong, Z.; Xia, Y.; Duan, X. Light-driven micron-scale 3D hydrogel actuator produced by two-photon polymerization microfabrication. Sens. Actuators B Chem. 2020, 304, 127345. [CrossRef]

99. Palima, D.; Bañas, A.R.; Vizsnyiczai, G.; Kelemen, L.; Ormos, P.; Glückstad, J. Wave-guided optical waveguides. Opt. Express 2012, 20, 2004-2014. [CrossRef]

100. Curtis, J.E.; Koss, B.A.; Grier, D.G. Dynamic holographic optical tweezers. Opt. Commun. 2002, 207, 169-175. [CrossRef]

101. Sinclair, G.; Jordan, P.; Courtial, J.; Padgett, M.; Cooper, J.; Laczik, Z. Assembly of 3-dimensional structures using programmable holographic optical tweezers. Opt. Express 2004, 12, 5475-5480. [CrossRef]

102. Čižmár, T.; Romero, L.C.D.; Dholakia, K.; Andrews, D.L. Multiple optical trapping and binding: New routes to self-assembly. J. Phys. B At. Mol. Opt. Phys. 2010, 43. [CrossRef]

103. Svoboda, K.; Block, S.M. Optical trapping of metallic Rayleigh particles. Opt. Lett. 1994, 19, $930-932$. [CrossRef]

104. Nishiguchi, A.; Zhang, H.; Schweizerhof, S.; Schulte, M.F.; Mourran, A.; Möller, M. 4D Printing of a Light-Driven Soft Actuator with Programmed Printing Density. ACS Appl. Mater. Interfaces 2020, 12, 12176-12185. [CrossRef]

105. Kaynak, M.; Ozcelik, A.; Nama, N.; Nourhani, A.; Lammert, P.E.; Crespi, V.H.; Huang, T.J. Acoustofluidic actuation of in situ fabricated microrotors. Lab. Chip 2016, 16, 3532-3537. [CrossRef] [PubMed]

106. Soreni-Harari, M.; Pierre, R.S.; McCue, C.; Moreno, K.; Bergbreiter, S. Multimaterial 3D Printing for Microrobotic Mechanisms. Soft Robot. 2020, 7, 59-67. [CrossRef] [PubMed]

107. Lind, J.U.; Busbee, T.A.; Valentine, A.D.; Pasqualini, F.S.; Yuan, H.; Yadid, M.; Park, S.; Kotikian, A.; Nesmith, A.P.; Campbell, P.H.; et al. Instrumented cardiac microphysiological devices via multimaterial three-dimensional printing. Nat. Mater. 2016, 16, 303-309. [CrossRef] [PubMed]

108. Askari, M.; Tuck, C.J.; Hu, Q.; Hague, R.J.M.; Wildman, R.D. Multimaterial Manufacture Through Combining Optical Tweezers with Multiphoton Fabrication. J. Laser Micro Nanoeng. 2019, 14, 80. 
109. Kuthe, S. Multimaterial 3D Printing of a Mechanically Representative Aortic Model for the Testing of Novel Biomedical Implants. Master's Thesis, KTH Royal Institute of Technology, Stockholm, Sweden, 2019.

110. Elomaa, L.; Yang, Y.P. Additive Manufacturing of Vascular Grafts and Vascularized Tissue Constructs. Tissue Eng. Part B Rev. 2017, 23, 436-450. [CrossRef]

111. Ovsianikov, A.; Schlie, S.; Ngezahayo, A.; Haverich, A.; Chichkov, B.N. Two-photon polymerization technique for microfabrication of CAD-designed 3D scaffolds from commercially available photosensitive materials. J. Tissue Eng. Regen. Med. 2008, 1, 443-449. [CrossRef]

112. Xing, J.F.; Zheng, M.L.; Duan, X.M. Two-photon polymerization microfabrication of hydrogels: An advanced 3D printing technology for tissue engineering and drug delivery. Chem. Soc. Rev. 2015, 44, 5031-5039. [CrossRef]

113. Richter, B.; Hahn, V.; Bertels, S.; Claus, T.K.; Wegener, M.; Delaittre, G.; Barner-Kowollik, C.; Bastmeyer, M. Guiding Cell Attachment in 3D Microscaffolds Selectively Functionalized with Two Distinct Adhesion Proteins. Adv. Mater. 2016, 29. [CrossRef]

114. Raimondi, M.T.; Eaton, S.M.; Nava, M.M.; Lagana, M.; Cerullo, G.; Osellame, R. Two-photon laser polymerization: From fundamentals to biomedical application in tissue engineering and regenerative medicine. J. Appl. Biomater. Funct. Mater. 2012, 10, 56-66. [CrossRef]

115. Van Hoorick, J.; Gruber, P.; Markovic, M.; Rollot, M.; Graulus, G.-J.; Vagenende, M.; Tromayer, M.; Van Erps, J.; Thienpont, H.; Martins, J.C.; et al. Highly Reactive Thiol-Norbornene Photo-Click Hydrogels: Toward Improved Processability. Macromol. Rapid Commun. 2018, 41, e1800181. [CrossRef]

116. Ma, Z.-C.; Zhang, Y.-L.; Han, B.; Hu, X.-Y.; Li, C.-H.; Chen, Q.-D.; Sun, H.-B. Femtosecond laser programmed artificial musculoskeletal systems. Nat. Commun. 2020, 11, 4536. [CrossRef] [PubMed]

Publisher's Note: MDPI stays neutral with regard to jurisdictional claims in published maps and institutional affiliations. 